\title{
Electromagnetically generated extracorporeal shockwaves for fragmentation of extra-and intrahepatic bile duct stones: indications, success and problems during a 15 months clinical experience
}

\author{
M Staritz, A Rambow, A Grosse, A Hurst, A Floth, P Mildenberger, M Goebel, Th Junginger, \\ $\mathrm{R}$ Hohenfellner, $M$ Thelen, $\mathrm{K}$ and $\mathrm{H}$ Meyer zum Büschenfelde
}

\begin{abstract}
Electromagnetically generated extracorporeal shock waves (without waterbath) were applied after intravenous premedication with 10-15 $\mathrm{mg}$ diazepam and $100 \mathrm{mg}$ tramadol in the treatment of 33 patients (aged 32 to 91 years) with multiple intrahepatic stones $(n=4)$ or huge common bile duct stones $(n=29,18-30$ $\mathrm{mm}$ in diameter), which could not be removed by conventional endoscopy. Stone disintegration was achieved in $70 \%$ of common bile duct stones and in all intrahepatic concrements after 800 - 7500 discharges, which were applied during one $(n=21)$, two ( $=6)$ or three sessions $(n=6)$. Apart from mild fleabite-like petechiae at the side of shock wave transmission no other side effects were observed for a total of 51 procedures. We believe electromagnetically generated shock waves are safe, easy to apply, and relatively effective in the therapy of common bile duct and intrahepatic stones.
\end{abstract}

First generation extracorporeal shock wave sources disintegrate $97 \%$ of kidney stones. ${ }^{12}$ Gall bladder and common bile duct stones were also recently treated in selected patients. ${ }^{3+}$ The technique available thus far, however, required immersion of the patient's body in a tank of degassed water. Therefore, the procedure was inconvenient, time consuming, and relatively expensive. The high pressure of shocks (up to 1000 bar) generated by underwater-sparkdischarge caused pain and general anaesthesia was necessary in most patients. ${ }^{34}$ Second generation shock wave devices do not require the use of a waterbath. New techniques for generation of shock waves were incorporated into these machines - for example, shock wave generation by piezo crystals, ${ }^{5}$ or an electromagnetic coil. ${ }^{67}$ We report on our 15 months' clinical experience which shows indications, success, and problems of the new procedure.

\section{Methods}

PATIENTS AND PATIENT SELECTION From October 1986 to December 1987 a total of 174 patients with common bile duct stones were admitted to our department. Approximately half of these patients were preselected by other gastroenterologists, who considered endoscopic treatment of these patients either too difficult or too risky to be performed in a municipal hospital.

Typical problems were intrahepatic calculi (four), large or impacted bile duct stones, bile duct stenosis with concrements proximal to the stenosis, patients with juxtapapillary diverticulum or previous Billroth-II-resection of the stomach. Out of a total of 174 patients (Table) 150 underwent conventional endoscopic sphincterotomy. Eleven patients received transpapillary endoprosthesis, because they were unfit for other procedures. In 13 cases small calculi could be removed after nitroglycerine relaxation of the bile duct sphincter. ${ }^{8}$ The remaining 33 patients, aged between 32 and 91 years, were treated by extracorporeal shock waves. They presented with bile duct stones which were too large $(18-30 \mathrm{~mm})$ to be snared using a Dormia probe, or too hard for mechanical lithotripsy..$^{9}$ In seven patients we considered a large sphincterotomy to be unsafe because of juxtapapillary duodenal diverticulum (four), or because of previous Billroth-IIresection (two-thirds resection) of the stomach (three).

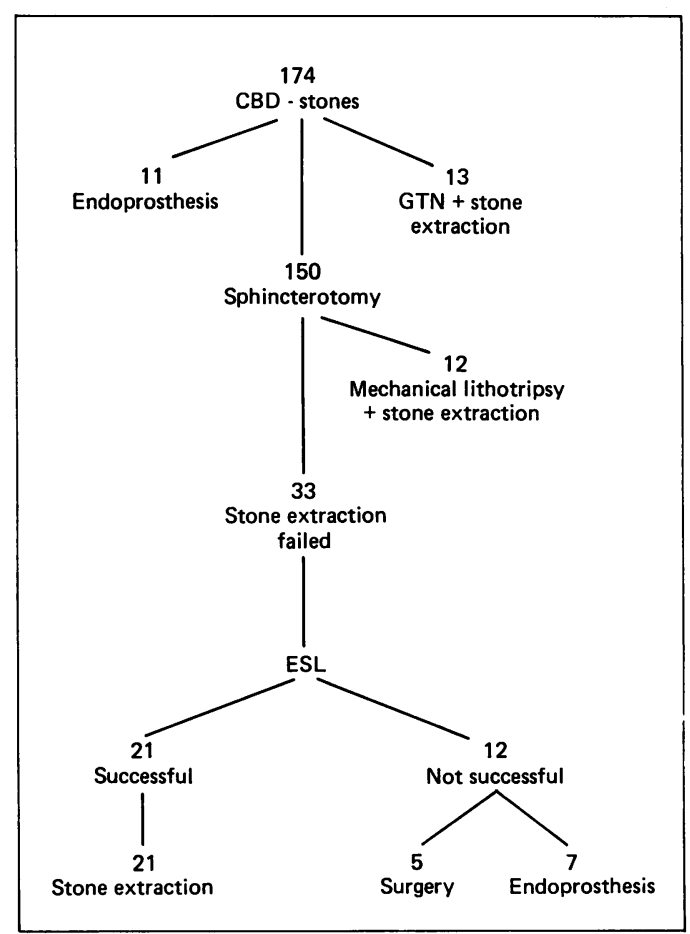

TABLE Therapeutic approach to common bile duct stones ( I Dept of Medicine, University of Mainz, October 1986December 1987).

I Medical Department,
Urological Department,
Radiological
Department, Surgical
Department, University
of Mainz,
Langenbeckstraße 1, D -
6500 Mainz, FRG
M Staritz
A Rambow
A Grosse
A Hurst
A Floth
P Mildenberger
M Goebel
Th Junginger
R Hohenfellner
M Thelen
K and H Meyer zum
Büschenfelde
Address for correspondence:
Martin Staritz, PM, PD, I
Medizinische Klinik und
Poliklinik(I Medical
Department), Johannes
Gutenberg Universität Mainz,
Langenbeckstraße 1, D - 6500
Mainz, Fed Rep of Germany
Accepted for publication
26 April 1989




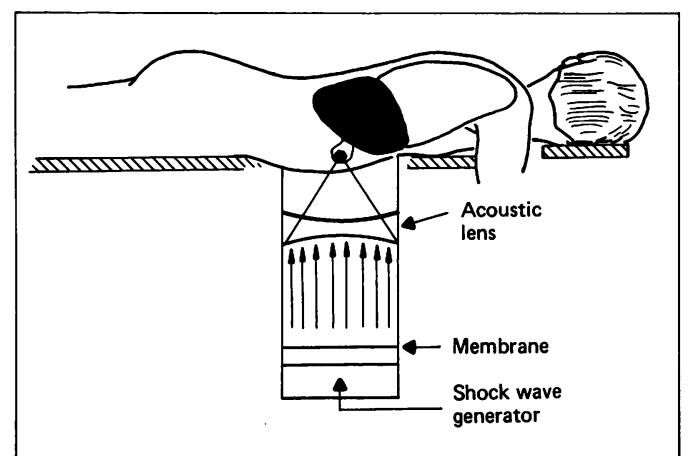

Figure 1: Second generation lithotriptor (Siemens Lithostar) generating shockwave energy by discharging an electromagnetical coil.

Four patients had stones in the intrahepatic bile ducts, which could not be removed endoscopically. An operative approach was thought to be of high risk, difficult, and likely not to be successful.

ENDOSCOPY, COMPUTED TOMOGRAPHY AND ADMINISTRATION OF EXTRA-

CORPOREAL SHOCK WAVES

In all patients endoscopic retrograde cholangiopancreaticography (ERCP) was performed using standard techniques. Patients selected for lithotripsy underwent computed tomography to measure radiological stone density.

During a second ERCP investigation a nasobiliary probe was inserted into the common bile duct for injection of contrast material (Rayvist $^{\circledR}$, Schering, Berlin, West Germany). Before shock wave lithotripsy patients were premedicated with 10 to $15 \mathrm{mg}$ diazepam and 100 mg tramadol (Tramal ${ }^{\circledR}$, Grünenthal, Aachen,
West Germany). The concrements were visualised by two dimensional fluoroscopy after injection of contrast material through the nasobiliary probe.

Shock waves were produced by a SiemensLithostar ${ }^{\circledR}$ (Siemens, Erlangen, West Germany). An electro-magnetic coil moved a membrane which was connected to an internal water pathway. This shock wave source generates the pressure wave by an electromagnetic membrane which compresses a waterbath inside of the machine. Shock energy is focused by an acoustic lens and transmitted into the body of the patient through a flexible membrane and a gel. The patients were lying in a prone position (Fig 1). Immersion of the body in water is not required.

Shocks were applied continuously until stone disintegration was visible or up to a maximum number of 2500 discharges. If necessary, a second or third session of lithotripsy followed one day thereafter.

Endoscopic removal of the fragments was attempted in all patients one day after administration of shock waves. Therapy was considered unsucessful when three sessions of shock wave administration had not been sufficient to allow endoscopic removal of the whole stone or its fragments. Endoscopy (ERCP) was also performed in patients without visible stone disintegration.

\section{FOLLOW UP INVESTIGATIONS}

All patients underwent follow up investigations for at least three days after shock wave administration. Follow up consisted of an immediate physical examination, laboratory tests including SGOT, SGPT, gamma-GT,

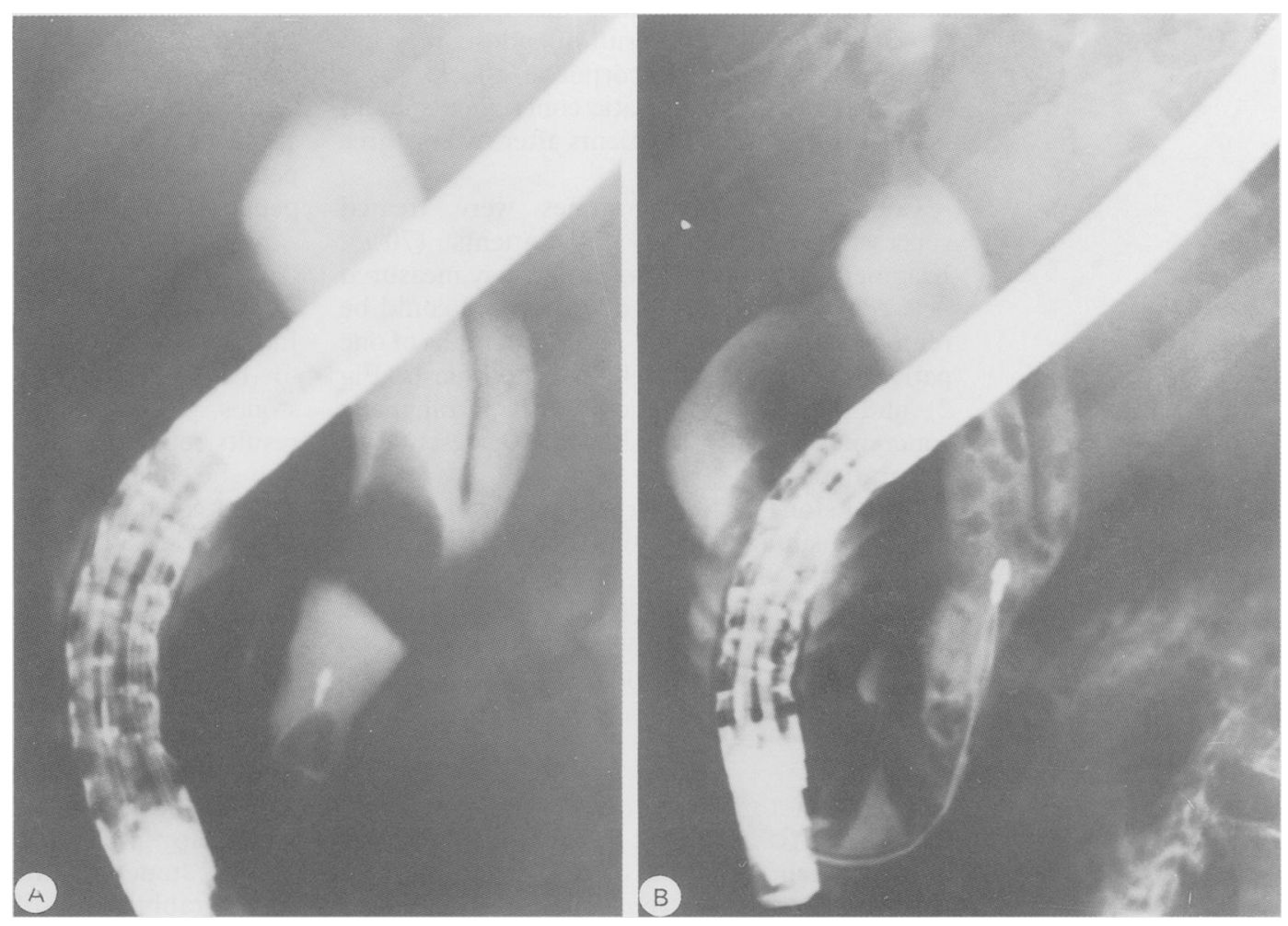

Figure 2: Common bile duct stone (a) which is too big to be snared with the Dormia probe. After administration of 1.800 shock waves the stone is disintegrated into tiny fragments $(b)$ which can be removed easily by a Dormia probe. 

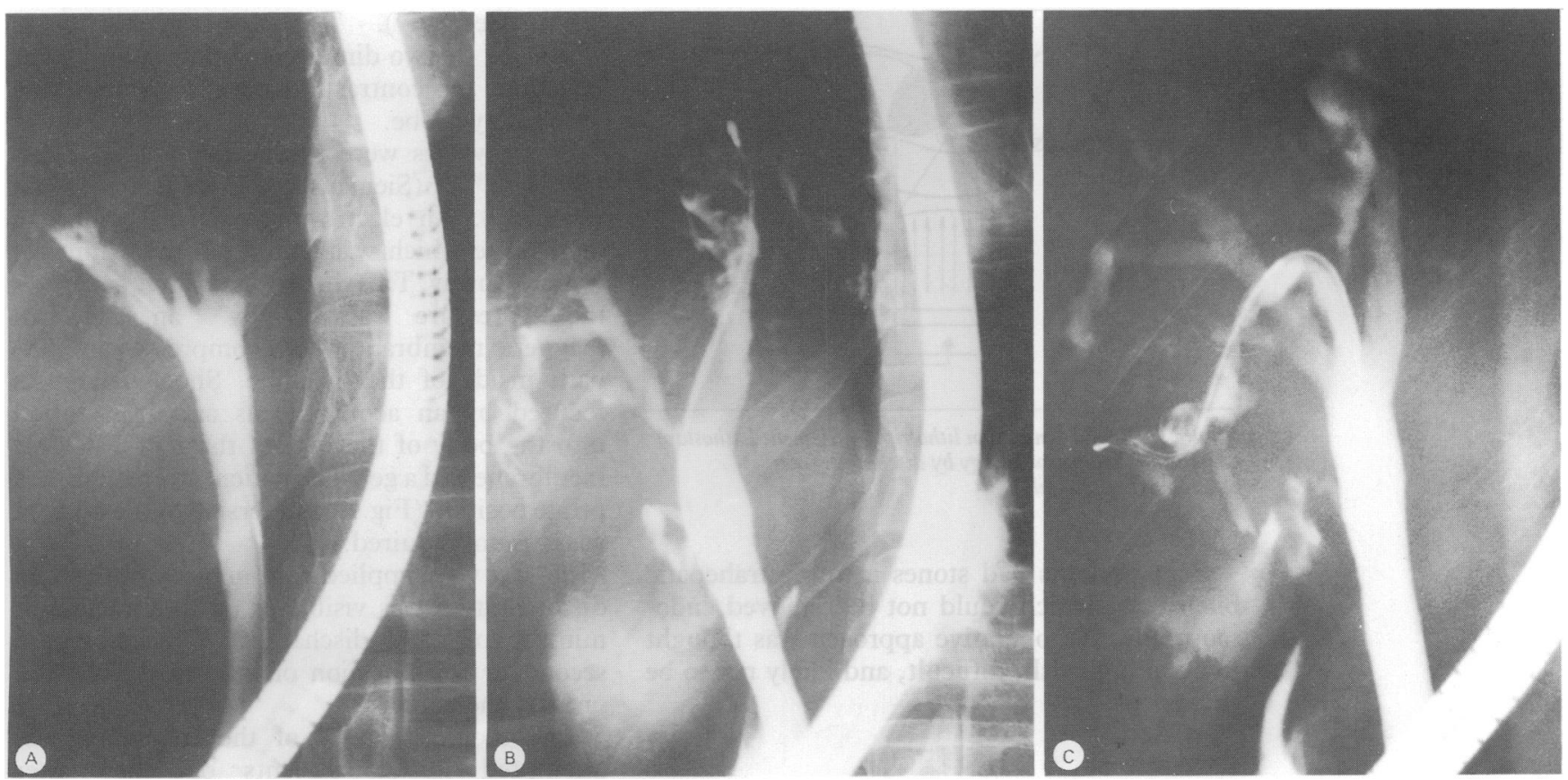

Figure 3: Intrahepatic bile duct stones: Before therapy all intrahepatic bile ducts are filled with stones and contrast material can not advance into the intrahepatic bile ducts $(a)$. After two sessions $(b)$ and a third session $(c)$ the bile ducts are nearly clear and removal of fragments remaining in the bile duct is possible by means of endoscopy.

pancreas enzymes, lipase, amylase, creatinin tests, complete blood count on the day of therapy and on the first and second day thereafter, as well as ultrasonography of the abdomen, particularly of liver and pancreas, and chest radiograph.

\section{Results}

SHOCK WAVE LITHOTRIPSY

All patients tolerated shock wave lithotripsy very well. The duration of shock wave administration ranged from 22 to 70 minutes (mean 40 minutes). No complications as a result of endoscopies and administration of extracorporeal shock waves were observed. Intrahepatic concrements could be disintegrated in all patients after two or three sessions.

Common bile duct stones were treated successfully in 21 of 29 patients $(70 \%)$. Fragments remaining after lithotripsy measured between 1 and $8 \mathrm{~mm}$ in diameter and could be removed endoscopically. The radiographs of one patient presenting with choledocholithiasis (Fig 2) and of another patient with intrahepatic concrements (Fig 3) are shown as representative illustrations.

Minor stone particles from stones which could not be disintegrated after three sessions also passed through the nasobiliary probe. Surprisingly, four impacted stones which were initially observed to be unaffected by the shocks, disintegrated after being touched with the Dormia probe.

SUCCESS OF LITHOTRIPSY AND

RADIOLOGICAL STONE DENSITY

Stones which could not be disintegrated had a radiological density from 0 to $\mathbf{4 0}$ Hounsfield Units (HU) as assessed by computed tomography.
Successful lithotripsy was achieved in stones with 60 to $190 \mathrm{HU}$, except in two patients who had undergone Billroth-II-resection, and in whom the duodenal stump was filled with air which probably interposed between shock wave source and stone.

\section{SIDE EFFECTS OF THERAPY}

None of the patients presented with clinical complications. Only in one female patient a rise of the transaminases from twice the normal value before to $400 \mathrm{U} / 1$ after lithotripsy was observed. In contrast with these laboratory findings, the patient experienced no clinical symptoms. Characteristically, however, shock wave application always caused mild fleabite like petechiae of the skin on the side of shock wave penetration.

\section{Discussion}

Extracorporeal shock wave sources were shown to be effective in the treatment of renal stones. ${ }^{1256}$ Our in vitro experiments ${ }^{7}$ and the results reported here show that gall stones can also be disintegrated by electromagnetically generated shocks. The procedure is safe, easy to apply and relatively effective. This could also be shown for piezo technique ${ }^{1113}$ and under water spark discharge. ${ }^{12}$ For therapy of bile duct stones electromagnetically generated shocks (Siemens Lithostar ${ }^{\circledR}$ ) compare favourably with under water spark discharge because this technique still requires immersion of the patient in a water bath. ${ }^{12}$ Piezo technique does not provide radiological focusing of the stone which is necessary for therapy of bile duct stones.

Gall stone fragmentation, however, is a considerably more difficult procedure than the disintegration of kidney stones. This fact is shown by the disintegration rate, energy required 
for disintegration, and size of fragments remaining after lithotripsy.

Whereas kidney stones were fragmented with our electromagnetically generated shock waves in $97 \%$ of patients, ${ }^{6}$ gall stone disintegration was achieved in only $70 \%$. According to our clinical experience,${ }^{6}$ kidney stones were easily broken up at an energy level generated by $15 \mathrm{kv}$. Gall stones could not be disintegrated at this energy either in vivo or in vitro.' Energy required for the fragmentation of gall stones was in the upper range of the available capacity (discharge voltage $20 \mathrm{KV}$ ).

The use of computed tomography may improve the disintegration rate by better selection of patients, as according to the results obtained by this study, stones with low radiological density (below $40 \mathrm{HU}$ ) - as determined by computed tomography - are likely to resist shockwaves.

After 15 months of clinical experience, we consider electromagnetically generated shock waves to be a reliable aid to improve indication of operative endoscopy. In selected patients high risk surgical procedures may be avoided and replaced by conservative treatment.

Successful therapy, however, required between three and five ERCP investigations and between one and three lithotripsy sessions for each patient, suggesting that the combination of endoscopic and shock wave therapy may be time consuming in most of the patients. Thus economic considerations require further comparison with other possible methods for therapy of huge biliary stones like stone dissolution, electrohydraulic and laser lithotripsy. Only randomised studies can evaluate the benefit of combined shock wave therapy and operative endoscopy in clinical practice.

1 Chausy C, Brendel W, Schmiedt E. Extracorporeally induced destruction of kidney stones by shock waves. Lancet 1980; ii: 1265-68.

2 Challah S, Mays NB. The randomised controlled trial for the evaluation of new technology: a case study. $\mathrm{Br}$ Med $\mathcal{F} 1986$ 292: 877-9.

3 Sauerbruch T, Delius M, Paumgartner G, et al. Fragmentation of gallstones by extracorporeal shock waves. $N \mathrm{Engl} / \mathrm{F} \mathrm{Med}$ 1986; 314: 818-22.

4 Sackmann M, Delius M, Sauerbruch T, et al. Shock-wave lithotripsy of gallbladder stones. The first 175 patients. NEnglf Med 1988; 318: 393-7.

5 Philip T, Kellett MJ, Whitfield HN, Wickham JEA. Painless lithotripsy: experience with 100 patients. Lancet 1988; i: $41-3$.

6 Wilbert DM, Riedmiller H, Alken P, Hohenfellner, R. Zweite Generation der extrakorporalen Stofiwellenlithotripsic Generation der extrakorporalen Stopwellenlithotripsi

7 Staritz M, Rambow A, Mildenberger P, et al. Electromagnetically generated extracorporeal shock waves for gallston lithotripsy: in vitro experiments and clinical relevance. Eur f C.lin Invest 1989; 19: 142-5.

8 Staritz M, Poralla T, Dormeyer HH, Meyer zum Büschenfelde $\mathrm{KH}$. Endoscopic removal of common bile duct stone through the intact papilla following medical sphincte dilation. Gastroenterolgy 1985; 88: 1807-11.

9 Demling L, Seuberth K, Riemann JF. A mechanical lithotripter. Endoscopy 1982;14: 100-1.

10 Staritz M, Ewe K, Meyer zum Büschenfelde KH. Mechanical gallstone lithotripsy in the common bile duct - in-vitro and in-vivo experience. Endoscopy 1983; 15: 316-7.

11 Hood K, Keightley A, Dowling AR, Dick JA, Mallison CN Piezo-ceramic lithotripsy of gallbladder stones: initial Piezo-ceramic lithotripsy of gallbladder ston

12 Sauerbruch $T$, Stern $M$ and the study group for shock wave lithotripsy of bile duct stones: Fragmentation of bile duct stones by extracorporeal shock waves after failure of routine stones by extracorporeal shock waves after failure of routine
endoscopic measures. [Abstract]. Gastrornterology 1988; 94: end 401

13 Johnson AG, Ross B, Milner PC, Birch S. Gallstone lithotripsy Lancet 1988; ii: 458 [Letter]. 